\title{
LA TORRE ALMENARA DE SAN GARCÍA, ALGECIRAS (S. XVII-XVIII). RECUPERACIÓN VIRTUAL DE UNA ESTRUCTURA MILITAR GRACIAS A LA TECNOLOGÍA
}

\author{
Pablo Aparicio Resco ${ }^{1}$
}

\section{Resumen:}

La reconstrucción virtual de la torre almenara de San García se enmarca dentro de las actuaciones para crear en Gibraltar el Centro de Interpretación de la Reserva de la Biosfera Intercontinental del Mediterráneo "Estrecho de Gibraltar", un proyecto llevado a cabo por la empresa Geasense. Actualmente sólo se conserva parte de la cimentación de esta torre defensiva por lo que la reconstrucción virtual de la misma tuvo que ser realizada en base a paralelos bien documentados a lo largo de la costa sur de nuestra Península. Este proyecto ha permitido mostrar cómo pudo ser en el pasado la torre, cuál fue su función y su valor patrimonial para las gentes de la Bahía de Algeciras.

\section{Palabras clave:}

Arqueología virtual, edificación militar, historia moderna, reconstrucción virtual

\section{Abstract:}

The virtual reconstruction of the defence tower of San García is a part of the actions achieved to create in Gibraltar an interpretation center called Centro de Interpretación de la Reserva de la Biosfera Intercontinental del Mediterráneo "Estrecho de Gibraltar", a project carried out by the company Geasense. Nowadays we are only preserving a part of the foundation of this defensive tower so its virtual reconstruction had to be based on well-documented similar constructions found along the southern coast of the Peninsula. This project is allowing to show how it could be, its function, and to explain its value for the people of the Bay of Algeciras in the past.

\section{Key words:}

Virtual Archaeology, military building, modern history, virtual reconstruction

1 PAR - Tecnologías de Representación Gráfica del Patrimonio. Email: aparicio.pablo89@gmail. com; Twitter: @ArcheoPablo; Web: www.parpatrimonio.com 


\section{Introducción}

La torre-almenara se emplazó en la parte más alta de la Punta de San García (Coordenadas: $36^{\circ} 06^{\prime} 25^{\prime \prime} \mathrm{N} / 5^{\circ} 26^{\prime} 02^{\prime \prime} \mathrm{O}^{2}$ ) y constituye un ejemplo de construcción militar para la vigilancia y defensa de la costa de este punto estratégico de la península. Actualmente se conservan unos restos muy pobres de la misma que han sido documentados mediante fotogrametría digital. Para su documentación, hemos contado con la toma fotográfica realizada por María Valencia, de Geasense, que nos ha permitido realizar un sencillo modelo fotogramétrico de los cimientos visibles sobre el que podremos comenzar a levantar la reconstrucción virtual de la torre.

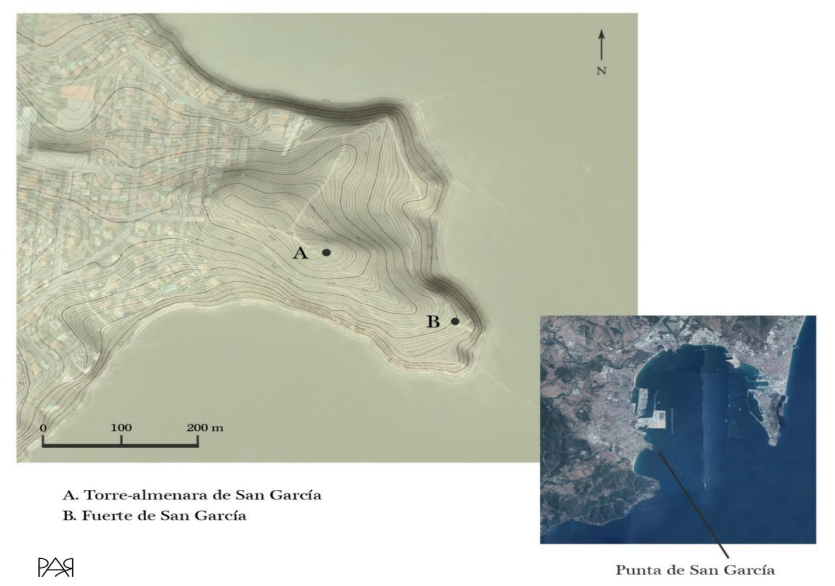

Fig. 1. Vista cenital del modelo LIDAR de la Punta de San García (Algeciras), con sus curvas de nivel, junto con la ortofoto actual de la Bahía de Algeciras en la que se indica su posición. Con la letra A se señaliza la situación de la Torre de San García sobre la Punta.

\section{Documentación histórica de la Torre de San García}

El primer paso -y quizás el más importante- para poder llevar a cabo una reconstrucción virtual fiable es el proceso de documentación y análisis histórico/ arqueológico de la propia estructura que se vaya a documentar. El cabo conocido como la Punta de San García es un enclave estratégico natural que se encuentra entre dos buenos fondeaderos, bien abrigados de los vientos dominantes del Estrecho de Gibraltar: la ensenada de Getares, al norte, y la desembocadura del río de la Miel, al sur³.

2 A. J. SÁEZ RODRÍGUEZ 2001, p. 238.

3 R. JIMÉNEZ-CAMINO ÁLVAREZ; A. J. SÁEZ RODRÍGUEZ; et al. 2009, p. 363. 
La Torre de San García es una de las numerosas estructuras de vigía y defensa que guardaba el Estrecho. Se trataba de una torre de marina ${ }^{4}$ que, tal cual la conocemos, debió ser levantada a finales del siglo XVI, en tiempos de Felipe II. Era una torre artillada que ejercía la función de vigilancia marítima y de trasmisión de señales ${ }^{5}$ en este punto de tanta importancia. En 1588 tenemos noticias de que existía una torre arruinada en este punto y se tuvo que proceder a su reconstrucción en el momento en el que se establecía el sistema de vigilancia costera que se mantendría durante la Edad Moderna, pues en 1608 ya tenemos una nueva noticia de su existencia en funcionamiento ${ }^{6}$. En la parte alta de este tipo de torres se colocaban hogueras que hacían las veces de señales de fuego y humo para indicar la presencia enemiga en la costa. Un antiguo viajero inglés, según recoge Sáez Rodríguez, hizo referencia al edificio con el nombre de "la torre de señales llamada Martello", usando una denominación genérica en su país para las torres de vigilancia ${ }^{7}$, y constituyendo también una muestra del uso principal que tenían este tipo de torres, que se comunicaban mediante ahumadas durante el día y con fuego durante la noche. Este tipo de defensa se caracterizaba por no disponer de guarniciones militares permanentes, obligando a sus ciudadanos a constituirse en milicias que salían a la defensa de la zona en estos puntos estratégicos en caso de ataque por parte, principalmente, de los piratas turco-berberiscos ${ }^{8}$.

La torre de San García era un edificio de piedra de planta circular, con base de calicanto ${ }^{9}$, de mayor grosor en la base y menor en la parte más alta, dentro del tipo de torre pequeña filipina. A finales del siglo XVII se dice que la torre es "de muy buena estofa" y "capaz de tres piezas de artillería arriva, y en los huecos de enmedio se pueden hazer oficinas para municiones" ${ }^{\prime 10}$. Pese a que existen divergencias en torno al diámetro de la torre, lo más probable es que éste fuera de 13 metros y medio en la base, lo que coincide con la huella de los cimientos que actualmente se puede contemplar en la Punta de San García. De la altura poco podemos saber pues no se conservan noticias de ella. Quizás lo único que tenemos son una planta y una sección que se conservan en el Archivo de la Región Militar Sur (Comandancia de Sevilla), realizadas en 1845 y que constituyen las primeras imágenes publicadas de este edificio ${ }^{11}$. Gracias a ellas es posible

4 R. VALDECANTOS 1996.

5 Idem.

6 A. J. SÁEZ RODRÍGUEZ 2001, p. 240.

7 Ibidem, p. 238

8 R. JIMÉNEZ-CAMINO ÁLVAREZ; A. J. SÁEZ RODRÍGUEZ; et al. 2009, p. 364.

9 Idem.

10 Aparece en el "Informe del Consejo de Castilla del 10 de Septiembre de 1691". SÁEZ RODRíGUEZ, A. J. (2001): p. 240

11 A.R.M.S.: Archivo de la Región Militar Sur (Comandancia de Sevilla). Plano de la Punta de SanGarcía, no 4. Doc. 457 (1845). 
recrear sus proporciones. Un buen paralelo, probablemente, sería el de la Torre de Gualdamesí aunque la Torre de San García tendría una sola estancia elevada, al estilo de la linense Torre Nueva. Sería quizás también parecida a la Torre del Tajo en Barbate, que alberga del mismo modo una única estancia interior. La torre tendría un acceso elevado a su única estancia orientado hacia el oeste, al que se llegaría mediante escalas de cuerda. En su terrado podría alojar artillería y, según sabemos, en 1616 la torre requería tres guardas y un artillero. En 1618 se insiste en la necesidad de la defensa de la misma, hablando de la importancia de tenerla bien ataviada con dos sacres, munición, pertrechos, cuatro mosquetes, etc., para defender una zona de la costa que frecuentemente se encontraba asaltada por el enemigo $^{12}$. Se trataba así de una torre artillada a medio camino entre la torre almenara de señales y el fuerte costero que se construirá más adelante. La torre de San García tenía enlaces ópticos con la almenara de Punta Carnero, al sur y con la de la Torre de Don Rodrigo, al norte, en el puerto de Algeciras ${ }^{13}$.

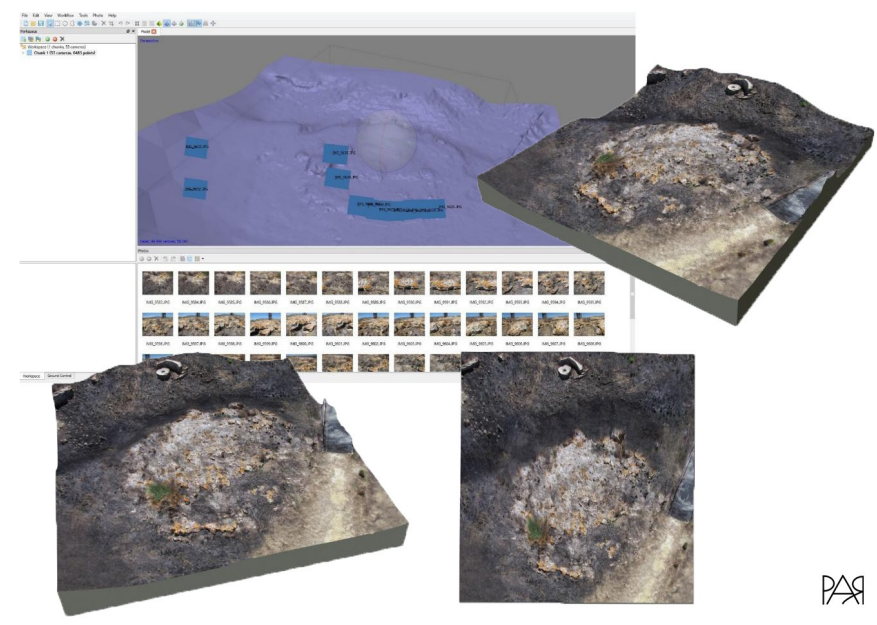

Fig. 2. Captura de pantalla en Photoscan del proceso de creación del modelo fotogramétrico de los restos actuales de la Torre de San García; tres renderizados del modelo 3D obtenido.

Entre la torre y el extremo oriental del cabo se construyó en el primer tercio del siglo XVIII el Fuerte de San García, un fuerte de artillería costera que, junto con los de Punta Carnero y la Isla Verde de Algeciras ${ }^{14}$, protegía el litoral sur de la ciudad. El proyecto del fuerte contemplaba la conservación de la Torre de San García dada su buena calidad, y su integración dentro del proyecto del Fuerte.

12 A. J. SÁEZ RODRÍGUEZ 2001, pp. 240 y 241.

13 A. J. SÁEZ RODRÍGUEZ 2001, p. 238.

14 Idem. 
Sabemos, sin embargo, que la torre quedó arruinada, poco a poco, a lo largo del siglo XVIII y que en 1769 fue reparada de nuevo, probablemente para ser usada exclusivamente como almacén de pólvora del Fuerte. Las labores de voladura de éste llevadas a cabo por los ingleses en 1810, aliados de España en la Guerra de la Independencia, afectaron de manera destacada a la torre, cuya bóveda quedó destruida ${ }^{15}$. Su deterioro fue progresivo durante las primeras décadas del siglo XIX pero debió de ser reparada en la década de 1840 porque en el 55 está en buen estado y sirve de alojamiento a los carabineros de la Real Hacienda.

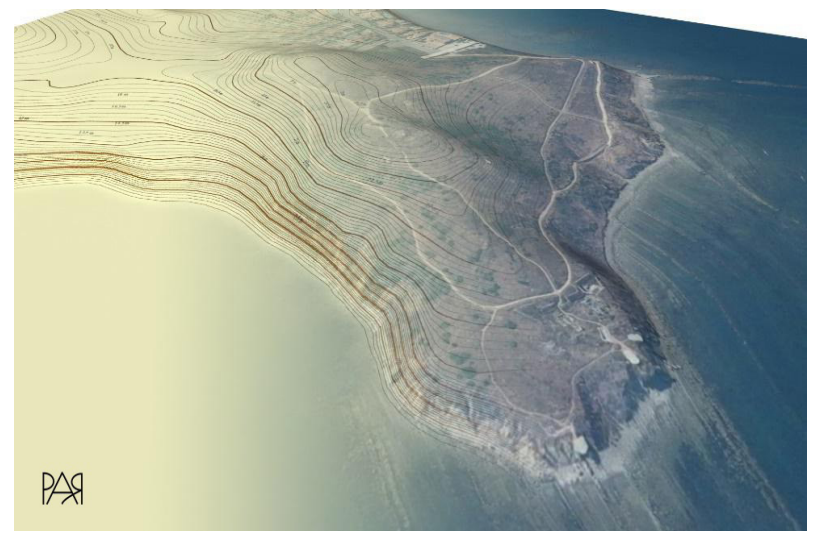

Fig. 3. Renderizado con curvas de nivel y ortofoto del modelo LIDAR de la Punta de San García.

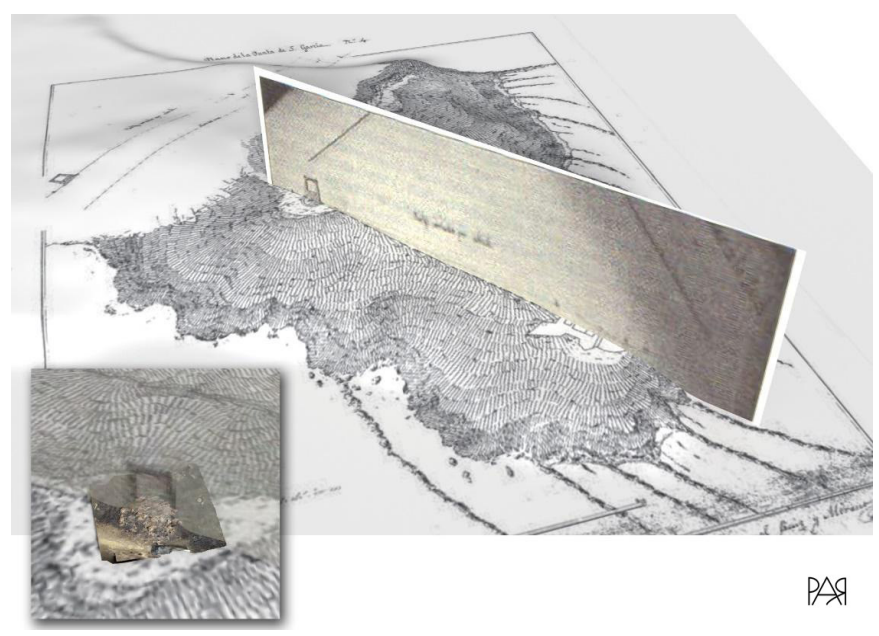

Fig. 4. Para comenzar a crear la torre se dispusieron la planta y la sección de la torre dibujadas en el s. XIX y el modelo fotogramétrico de los cimientos actuales en un entorno 3D en Blender.

15 Ibidem: pp. 240 y 241. 
Durante la Primera República fue escenario de un enfrentamiento entre los carabineros locales y el Batallón de Voluntarios de Algeciras por la posesión de armamento, en el marco de la constitución del Cantón Algecireño. El desmantelamiento definitivo de la torre llegó, probablemente, a finales del s. XIX cuando se levantó en sus inmediaciones una de las baterías provisionales del Ejército de Tierra para la defensa de la Bahía de Algeciras en $1898^{16}$.

Teniendo en cuenta los datos disponibles -que no son muchos- de la Torre de San García, se entiende que el mejor paralelo de la misma es la Torre del Tajo en Barbate $^{17}$.

\section{Proceso de realización de la reconstrucción virtual}

Para llevar a cabo el modelado de la torre -que ha sido realizado íntegramente en Blender- se ha dispuesto el plano de 1845 correctamente colocado sobre el MDT (modelo digital del terreno) LIDAR actual ${ }^{18}$. Después se colocó la sección llevada a cabo en la misma fecha exactamente en el punto que le corresponde, haciendo coincidir la planta de la torre con su alzado. Posteriormente fue posicionado el modelo fotogramétrico en $3 \mathrm{D}$ de los restos actuales de la torre.

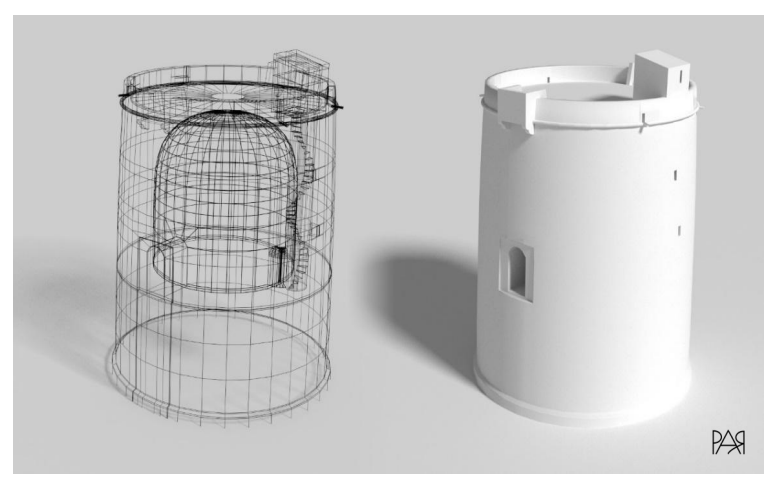

Fig. 5. Vista alámbrica y en blanco de un primer boceto de la reconstrucción virtual de la torre de San García.

\footnotetext{
16 Ibidem: pp. 241 y 242.
}

17 Esta opinión la comparte también el arqueólogo municipal de Algeciras, Rafael Camino, cuya ayuda ha sido inestimable para llevar a cabo con precisión la reconstrucción virtual de la torre. Fue él quien nos aconsejó sobre elementos como la cuerda de acceso a la torre, la garita superior, las ladroneras, la posición de los cañones directamente sobre el coronamiento del muro y no en troneras, etc.

18 Esta información geográfica, junto con la ortofoto del PNOA y las curvas de nivel de la Punta de San García, ha sido obtenida de la web del IGN (http://www.ign.es/ign/main/index.do). Consultado a 26/04/2015. 
A partir de fotografias de la Torre del Tajo, de la documentación gráfica de la Torre de San García conservada desde el siglo XIX y del modelo 3D fotogramétrico de sus cimientos se comenzó a modelar la reconstrucción virtual de la torre. Posteriormente, también en base a las imágenes actuales de la Torre del Tajo y de la de Gualdamesí, se recreó la textura, dejando ver la construcción de la torre con fábrica de mampostería y el recubrimiento con un enlucido que la protegía de las inclemencias del tiempo. Se decidió reconstruir el encalado en un momento en el que se había perdido parte de él para que así fuera posible contemplar también la fábrica interior y el realismo de la representación sea mayor.

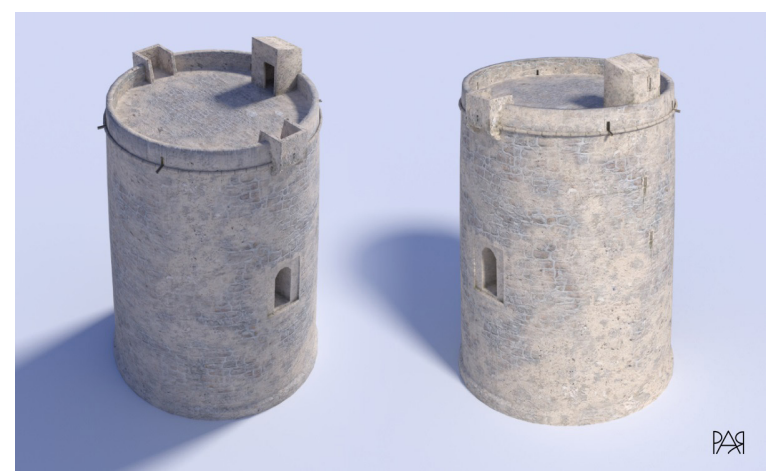

Fig. 6. Primer boceto en 3D de la torre de San García texturizado.

Se pensó que podría resultar interesante reconstruir también, tal y como nos dicen las citadas fuentes de 1616 y 1618, lo que contenía la torre por aquel entonces, a saber: dos sacres (culebrinas de bajo calibre), cuatro mosquetes, munición, pertrechos, tres guardas y un artillero. Su reconstrucción fue realizada en base a varios repositorios de imágenes entre los que destaca la información que podemos encontrar en Artillery Through the Ages: A short illustrated history of cannon, emphasizing types used in America ${ }^{19}$.

Así mismo, se llevó a cabo un proceso de documentación para recrear el resto de elementos que componen la escena, como los mosquetes o los morriones de los guardas ${ }^{20}$. El resto de los objetos reconstruidos (maderas, barriles, cajas,

19 A. MANUCY 2007; además se han consultado otras páginas web que tratan sobre el tema y que muestran, de forma más o menos detallada, cómo eran este tipo de piezas de artillería en la Edad Moderna. Por ejemplo, se han utilizado algunas de las infografías publicadas en esta entrada del blog "Amo del Castillo": http://amodelcastillo.blogspot.com.es/2011/09/artilleria-de-plaza-ysitio-2-parte-el.html Consultado a 26/04/2015.

20 Se han consultado varias publicaciones y páginas web entre las que se encuentran: http://www. aetasrationis.com/uploads/2/0/8/2/2082620/mosquetes_espaoles_en_la_batalla_de_almansa.pdf; http://www.juntadeandalucia.es/culturaydeporte/museos/media/docs/MACSE_armas.pdf (Consultado a 26/04/2015) y http://es.wikipedia.org/wiki/Morri\%C3\%B3n\#mediaviewer/Archivo:Morri\%C3\%B3n_en_Sevilla.JPG (Consutado a 26/04/2015). 
sacos, etc.) son comunes a todas las épocas preindustriales por lo que se han utilizado objetos de archivo.

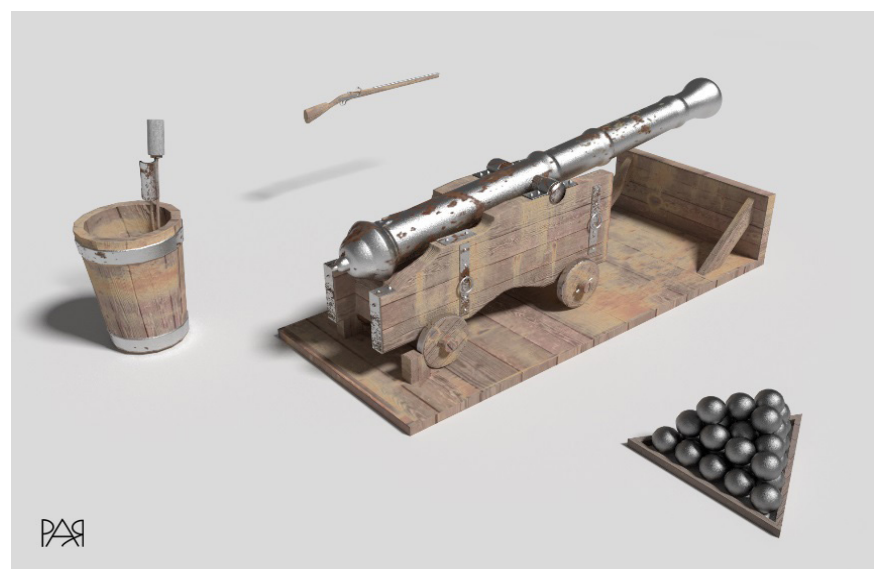

Fig. 7. Varios modelos 3D de objetos incluidos en la reconstrucción virtual de la torre.

De este modo, da la impresión de que se consigue hacer más didáctica la reconstrucción de la torre y ambientarla en la época referida (en torno a 1620) aunque se trata de un edificio que tuvo distintas fases de uso hasta principios del siglo XX.

Se ha llevado a cabo, además, una sección "manual" del modelo que nos permite ver de forma más didáctica las diferentes partes de la torre, obteniendo como resultado una infografía muy clara y explicativa de la torre.

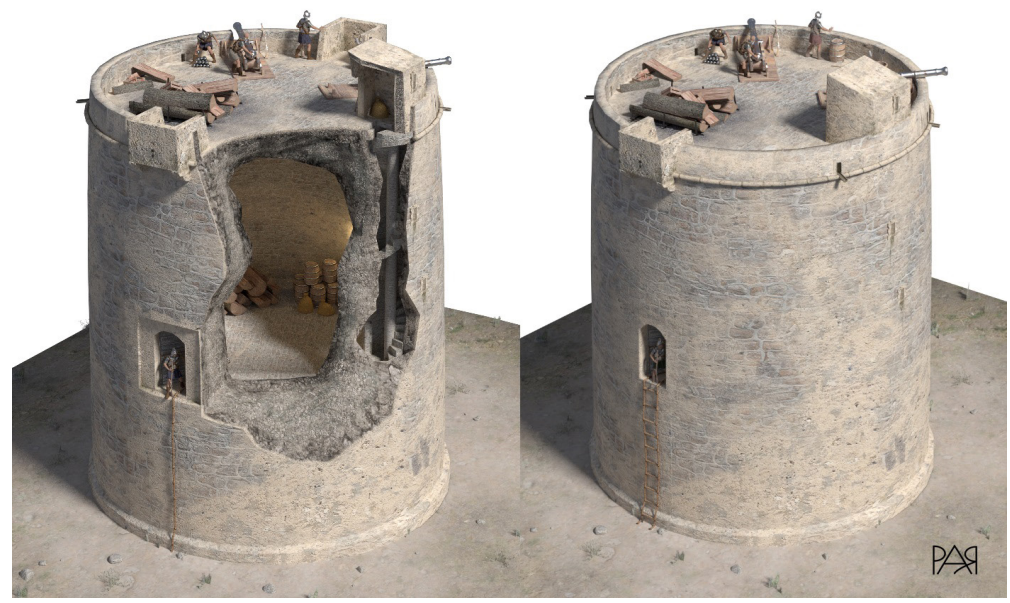

Fig. 8. A la izquierda se puede ver la reconstrucción virtual de la torre de San García, en un momento del proceso de su creación, con la sección realizada de forma manual para 
que se aprecie el interior. A la derecha, en cambio, se observa la reconstrucción virtual completa, sin la sección, y con la corrección de algunos detalles.

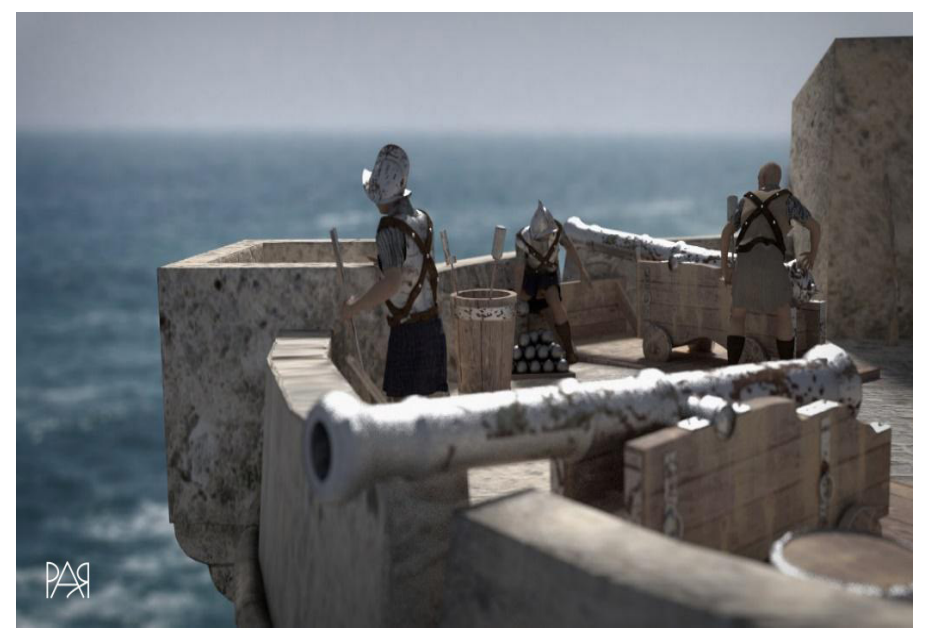

Fig. 9. Renderizado de detalle de la reconstrucción.

Posteriormente se ha usado el software de renderizado Lumion para llevar a cabo imágenes y animaciones que han permitido enriquecer el audiovisual final que se expondrá en el Centro de Interpretación para el que ha sido realizado esta reconstrucción. Así mismo, la reconstrucción virtual de la torre de San García ha sido ya dispuesta en un panel en la propia Reserva de la Biosfera de Algeciras.

Para la correcta comprensión de la autenticidad y el nivel de evidencia histórico arqueológica de cada parte de la reconstrucción se ha usado la escala de evidencia histórico-arqueológica.

\section{Conclusión}

Las reconstrucciones virtuales no son nunca cartas en blanco en las que podamos realizar un ejercicio de total imaginación que nos lleve a falsear la Historia. Tampoco son documentos que nos permitan saber con exactitud y sin sombra de duda cómo fue un determinado entorno de nuestro pasado. Son hipótesis gráficas que nos empujan a trazar una posible imagen de nuestra Historia, a asomarnos a los retazos de lo que un día quizás fue, sin tener nunca al cien por cien la seguridad de lo que vemos. Es por ello que este tipo de artículos, en los que se explican los pasos que nos han Ilevado a dar forma a una reconstrucción virtual de esta y no de otra manera, son fundamentales para que la Arqueología Virtual avance como disciplina científico-social. 


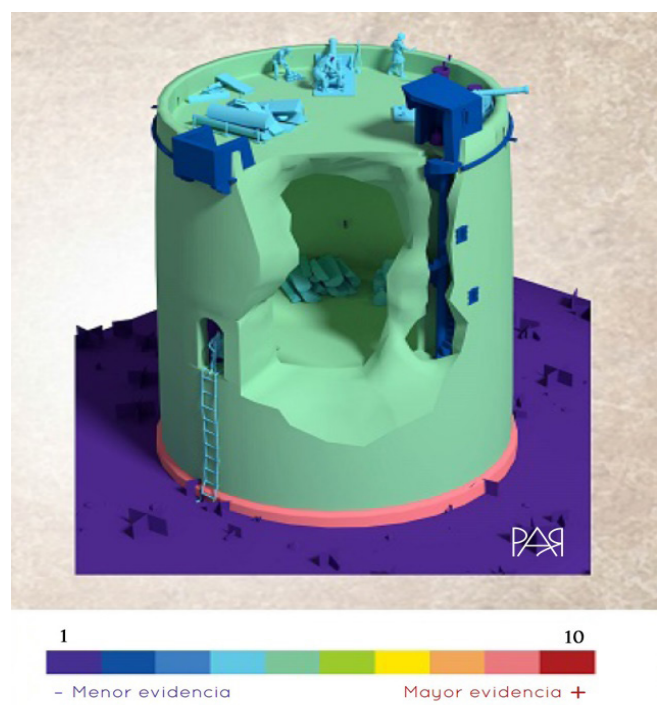

Fig. 10. Escala de evidencia histórico-arqueológica de la reconstrucción virtual de la torre de San García.

\section{Bibliografía}

A. J. SÁEZ RODRÍGUEZ: Almenaras en el Estrecho de Gibraltar. Las torres de la costa de la Comandancia General del Campo de Gibraltar. Instituto de Estudios Campogibraltareños, 2001.

A. MANUCY: Artillery Through the Ages. A Short Illustrated History of Cannon, Emphasizing Types Used in America. 2007.

A.R.M.S.: Archivo de la Región Militar Sur (Comandancia de Sevilla). Plano de la Punta de SanGarcía, no 4, Doc. 457, 1845.

R. JIMÉNEZ-CAMINO ÁLVAREZ; A. J. SÁEZ RODRÍGUEZ; et al.: "El fuerte costero de San García (s. XVIII): excavación y restauración del hornabeque", Caetaria, No 6-7, pp. 361-384, 2009.

R. VALDECANTOS: "Las torres de almenara del litoral de la provincia de Cádiz (las torres de marina): estudio tipológico y consideraciones terminológicas", Estudios de Historia y Arqueología Medievales, Nº XI, pp. 481-501, 1996. 